\title{
Numerical study on load-bearing capabilities of beam-like lattice structures with three different unit cells
}

\begin{abstract}
The design and analysis of lattice structures manufactured using Additive Manufacturing (AM) technique is a new approach to create lightweight high-strength components. However, it is difficult for engineers to choose the proper unit cell for a certain function structure and loading case. In this paper, three beam-like lattice structures with triangular prism, square prism and hexagonal prism were designed, manufactured by SLM process using AlSi10Mg and tested. The mechanical performances of lattice structures with equal relative density, equal base area and height, and equal length for all unit cells were conducted by Finite Element Analysis (FEA). It was found that effective Young's modulus is proportional to relative density, but with different affecting levels. When the lattice structures are designed with the same relative density or the same side lengths, the effective Young's modulus of lattice structure with triangular prism exhibits the maximum value for both cases. When the lattice structures are designed with the same base areas for all unit cells, the effective Young's modulus of lattice structures with square prism presents the maximum. FEA results also show that the maximum stress of lattice structures with triangular prisms in each comparison is at the lowest level and the stiffness-to-mass ratio remains at the maximum value, showing the overwhelming advantages in terms of mechanical strength. The excellent agreements between numerical results and experimental tests reveal the validity of FEA methods applied. The results in this work provide an explicit guideline to fabricate beam-like lattice structures with the best tensile and bending capabilities.
\end{abstract}

Keywords: Lattice structure; Unit cell; Additive Manufacturing (AM); Finite Element Analysis (FEA); Selective Laser Melting (SLM).

\section{Introduction}

Additive manufacturing (AM) technologies are able to provide the promising possibilities to create new design without a multitude of limitations by conventional processes, such as moulds and dies, casting etc. Lightweight design is one area that AM achieves well where it is impractical for other conventional fabrication technologies [13]. Currently there are two main methods of lightweight design, including cellular structure with unit cell [4-6] and topology optimization with advanced algorithm $[2,3,7]$. Topology optimization has only been used for maximum stiffness design to date but lacks sufficient capabilities for hierarchical design integrations at multiple scales [1]. Gervasi and Stahl [2] also found some types of topology optimization to show unrealistic presence of regions with intermediate densities. Lattice structure explores to achieve the balance between design convenience/efficiency and design accuracy by representative geometries to efficiently perform design tasks. Some researchers even tried to integrate lattice microstructures with its structural optimization to maximize the stiffness-to-mass ratio $[2,7,8]$.

Basically, the use of lattice structures and other cellular materials is motivated by where the material is needed and periodically or randomly arranged [9]. These periodic cellular lattice structures are advantageous in high performance features such as high specific stiffness and high strength, as well as the possibility of tailoring their properties by designing appropriate cell architecture $[6,10]$. By imagining a procedure to re-orienting the lattice elements, it is possible to make the lattice conform to principal stress direction [2], accomplishing the design and fabrication of lightweight parts. It makes cellular materials suitable for high value aero-space, medical and engineering products [11]. Besides, it is convenient to form the regular relationships between mechanical properties and geometrical parameters used to define the shape of unit cell.

It is known that the cellular lattice structure is built by repeatable unit cells as collected in the library of unit cells by Giannitelli [12]. In addition, many other unit cells are also proposed, like the triangular, square and hexagonal unit cells [13] for honeycombs, Schoen Gyroid [14], Kelvin cell [15], including closed cells and open cells that can be fabricated by SLM. The above mentioned unit cells were used in different applications. For example, 'Kelvin cell' unit cell which was investigated by Brennan-Craddock et al [15] was used to assess the capability of energy absorption [9]. Alzahrani et al. [16] carried out the design of truss-like cellular structures with triangular unit cells using relative density mapping method, which has great potential in lightweight design applications. Honeycombs 
are the typical structures defined by two-dimensional prismatic cellular materials of periodic meso-structures and have been primarily used in lightweight sandwich structures for their high out-of-line stiffness [17, 18]. Based on the belief that hexagonal honeycombs are valued for their combination of high strength and low density, Ju et al. [19] employed an in-plane linear elastic honeycomb model to compliant hexagonal periodic lattice structures, which turn out to achieve both high shear strength and high shear strain. As stated by Gibson and Ashby [17], cells in honeycombs are not always hexagonal. Ceramic and metal honeycombs used for exchangers and catalyst supports sometimes have square or triangular cells. Hence for light weight and load bearing, typically unit cells such as triangular, cubic and hexagonal are used.

The load bearing capability of each unit cell is also determined by the loading conditions. As an example, honeycomb with triangular unit cell is even stiffer compared to hexagonal honeycomb under the same axial stress. Through the comparison of triangular honeycombs, square honeycombs and hexagonal honeycombs under the same force by Ju and Summers [19], triangular honeycombs show the minimal value of normalized shear strain-shear strength, indicating the advantage of triangular honeycombs under shear force. Brenne et al. [20] gained insight into the impact of microstructure with square unit cells and local strains on the monotonic and cyclic behaviour under uniaxial and a more complex loading conditions by a plain sandwich structure under four-point-bending. It was found that most of the above mentioned publications focused on one certain type of unit cell in ideal model, no practical applications and most of the loads were axial compression $[1,11,14,21]$.

One critical challenge in realizing engineered lattice structures is the mechanical variation determined by shapes and sizes of struts composing the lattice due to the capability of AM process. Many researches have focused on the evaluation of mechanical properties of lattice structures over the past decades. Mathematical relationships or theoretical models [22-25], experimental study [5, 11, 19, 20] and Finite Element Method (FEM) [21, 26, 27], have been proposed to estimate the mechanical properties such as Young's modulus and ultimate strength. In the work done by Park et al [9], they investigated the elastic modulus of lattice structure filled with square unit cells. The result showed that the elastic modulus changes with the varying strut diameters and rotation angles. Papers in this area only focus on one specific unit cell and describe its mechanical properties by simple and limited number of samples $[1,11,14,22]$. It lacks of practical engineering applications, especially for the conformal structures with some certain unit cells. In another aspect, there are fewer comparisons among the potential unit cells used to conform to the practical load bearing parts. As pointed out by Jin et al. [18], an overall understanding of specimen size effects on the mechanical properties (modulus, strength, plateau stress and densification strain) in out-of-plane and in-plane directions is still unclear.

As there is no explicit guidance regarding to the preferable choice of potential unit cells, it is difficult for engineers to make a sound decision when selecting the unit cells to make conformal lattice structures. Fortunately, FEA has been successfully used for the prediction of mechanical properties of AM polymeric and composite scaffolds [28, 29]. However, some unit cells are so complex that besides taking up too much design space, their FEA models are also difficult to build and modify. Moreover, not all unit cells are designed for mechanical supporting structures, could be fabricated by AM process [12], or are suitable for beam-like structures. Even for supporting function unit cells, some of them also originated from triangular prism [30-32], cubic prism [20, 33-35] and hexagonal prism [19, $25]$ that are widely used in mechanical engineering.

As triangular prism, square prism and hexagonal prism are the most widely used unit cells in mechanical engineering, these were selected to be investigated in this work. The material used was AlSi10Mg alloy. It is a traditional cast alloy often used for die-casting that is also frequently used in SLM-fabricated components [36]. From the results by FEA, the corresponding mechanical performances, such as effective Young's modulus, maximum von Mises stress, and stiffness-to-mass ratio were classified and compared. The FEA results of Young's modulus were also verified by physical test with SLM manufactured AlSi10Mg samples.

\section{Lattice structures and geometry model}

\subsection{Lattice structures}

To date, a lot of lattice models were proposed based on AM techniques especially in biomaterials [22]. Biomaterials are designed to be biocompatible, to allow for bone ingrowth and optimal osseointegration, and to have the ability to 
deliver therapeutic agents [22]. However, from a mechanical engineering point of view, the principal function should be able to reduce weight while keeping the load bearing capability. The critical issue is therefore to investigate mechanical response of lattice structures. In this work, three unit cells, including triangular prism, square prism, and hexagonal prism constructed using strut at each edge as shown in Fig. 1(a) were investigated.

\subsection{Conformal lattice structures}

In this paper, another method to generate the lattice structure with traditional CAD software package Creo ${ }^{\circledR}$ was proposed and published by the authors [37]. The first step was to create a large scale lattice structures with the basic unit cells as displayed in Fig. 1(a). Here the basic unit cell is shaped by length, $L$, strut thickness with square crosssection, $t$, and height, $h$. One single layer of unit cells was firstly obtained by patterning in in-plane direction. This single layer was then repeated $N$ times in out-plane direction, where the distance was equal to $h$ between neighboring layers. This modelling method may cost relatively more time to generate each parametrical part due to scale features and large computations of Boolean operation, but is still a good proposal to build lattice structure for those who use Creo® only. Besides, as there will be more than one hundred models with different shape parameters in the following comparisons, it is more convenient to change and edit the varied structures by PLS file in Creo® [37].

(a)
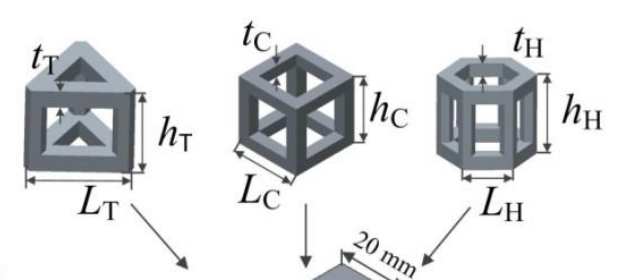

(b)

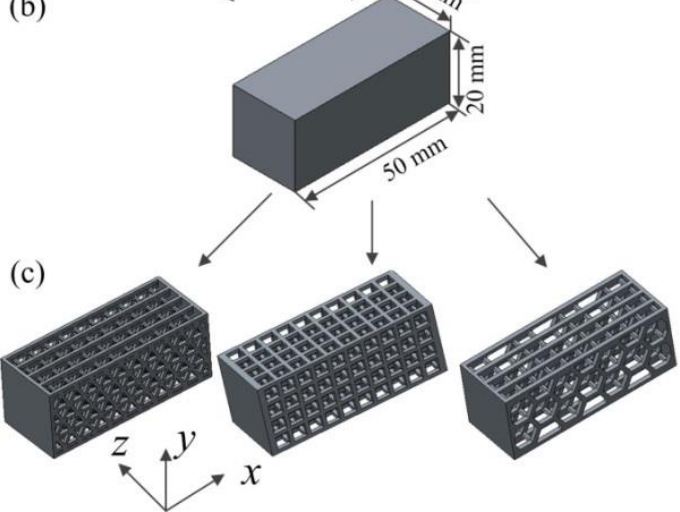

Fig. 1 Geometrical evolution of lattice structures with three unit cells, (a) 3D skeleton unit cells of triangular prism, square prism and hexagonal prism, (b) to be replaced solid volume $20 \mathrm{~mm} \times 20 \mathrm{~mm} \times 50 \mathrm{~mm}$, (c) three types of parametric lattice structures [37].

The representative volume element (RVE) method was often used to represent the cellular lattice structure [26] to investigate the mechanical properties, such as the effective Young's modulus $\left(E^{*}\right)$ and shear modulus. $E^{*}$ is a representative value to characterise the bulk mechanical performance of lattice structures with various types of unit cells $[22,24,38,39]$. The large scale lattice structures were then trimmed by RVE with a volume of $20 \mathrm{~mm} \times 20$ $\mathrm{mm} \times 50 \mathrm{~mm}$ as displayed in Fig. 1 (b). However, the tailored lattice structure had irregular cutting edges, which would result in incomplete unit cells which do not contribute to the structure as pointed out by Li [4], or cause stress free boundary as illustrated by Onck et al. [22]. The above mentioned cases should be avoided. Firstly, it is inconsistent with the stress condition at the boundary of the original solid part and secondly. The irregular cutting edges are usually non-convergent in FEA due to small patches. The solution in this project was that the irregular boundaries were connected and covered by ribs and caps as shown in Fig. 1(c). Here the cross-section of the ribs used is equal to that of the strut and the thickness of the caps is $1 \mathrm{~mm}$. With these design constraints, it intends to make it comparable that the only variation for the lattice structure is the shape parameters of the unit cell. 


\subsection{Design constraints based on AM}

Challenges to CAD design planning would be in the determination of the smallest manufacturable element, which in turn depends on the fabrication process and the material properties. The resolution of AM in creating components is an important basis for designing and fabricating cellular structure, as the thickness of the strut should not be smaller than the fabricating resolution. Firstly, the minimum pore should be able to avoid shrinkage and make it possible to remove the remaining powders though the open cells according to the powder based AM process. Secondly, the strength of the lattice structure is positively related to the strut thickness, hence it cannot be too small [40]. It should be noted that the characteristic lengths of the cells in meso-scale are in the range of 0.1 to $10 \mathrm{~mm}$ [4]. The minimum thickness applied by Wang et al. [40] was $0.15 \mathrm{~mm}$, which is proven to be fabricated well. For the maximum size, when the large unit cell size is greater than $5 \mathrm{~mm}$, it could not be built by SLM process since over hanging struts in the cells resulted in the occurrence of serious deformation [11], which is regarded to be the upper limitation on manufacturing of struts for complex cellular structure. In terms of lattice structure, it means the smallest feasible strut thickness is $0.15 \mathrm{~mm}$, while $L$ should be bigger than $t$, but less than $5 \mathrm{~mm}$. The thickness $h$ could be calculated by the number of layer in its thickness direction. The original solid part used in this paper is a rectangular beam-like structure $\left(20 \times 20 \times 50 \mathrm{~mm}^{3}\right)$. Since the purpose of this paper is to compare the mechanical properties of three conformal lattice structures with the same design variables, it is not important to get the accurate range of manufacturable dimensions, as long as it is within the resolution and manufacturability of the SLM process used in this paper.

\section{Finite element modelling methodology}

\subsection{Aluminium alloy AISi10Mg}

The aluminium alloy applied is AlSi10Mg from SLM Solutions. It is a widely used alloy for casting and in AM [41, 42]. The hypoeutectic alloy is near the eutectic composition $(12.5 \% \mathrm{Si})$ which is responsible for the excellent casting properties. According to the experiment by Kempen et al. [43], the mechanical properties of SLM-printed AlSi10Mg parts are higher or at least comparable to the casted AlSi10Mg in terms of very fine microstructure and fine distribution of Si phase. The Young's modulus of parts built in diagonal direction with layer thickness of $30 \mu \mathrm{m}$ is $63 \pm 4 \mathrm{GPa}$ and the Poisson's ratio is 0.33 .

\subsection{Mesh generation}

The complexity of the cellular lattice structure makes it computationally intensive and time-consuming for the discretization procedure during the mesh generation of the FEA analysis [39]. Solid element and beam element are normally applied to FEM of lattice structure and compared by Luxner et al. [10] and Smith et al. [27] . Tetrahedral element method was used to investigate the quasi-static compressive deformation process and stress evaluation in a full scale micro-lattice structure by Li [21]. Beam element method was found to be computational cheap, but straightforward modelling of vertex by beam elements suffers from two approximations [10]. The multiple volumes at overlapping domains and the possible constraints in the vicinity of vertices caused by the material aggregation in these domains were not included. However the distribution of the material in the intersection of the struts should be considered regarding to stiffness and density. On the contrary solid element has the advantage of all features of the structures' geometries. If scale lattice structures are built by beam elements in this project, it would take more time in modelling and defining the contact between solid ends and beam elements. Hence, it is preferable for the tailored design by Creo ${ }^{\circledR}$ and large number of repeating designs with scale lattices for this project. In this work, the combination of quadratic tetrahedron element tet 10 and 20 nodes hexahedron element hex 20 were used (Fig. 2). The conformal lattice structure was firstly divided into small sample parts and meshed by different element type, then merged into a single part. It is known that the accuracy of FE model depends on the element size and integration schemes. To use the appropriate element size, a mesh-sensitivity study was carried out using maximum von Mises stress to division of strut in $h$ direction as illustrated in Fig. 2. The fine mesh was generated by hexagon dominant multizone method. It was observed that the maximum von Mises stress converged when the element size was a quarter of the strut's thickness, which was $0.25 \mathrm{~mm}$ in this case. 


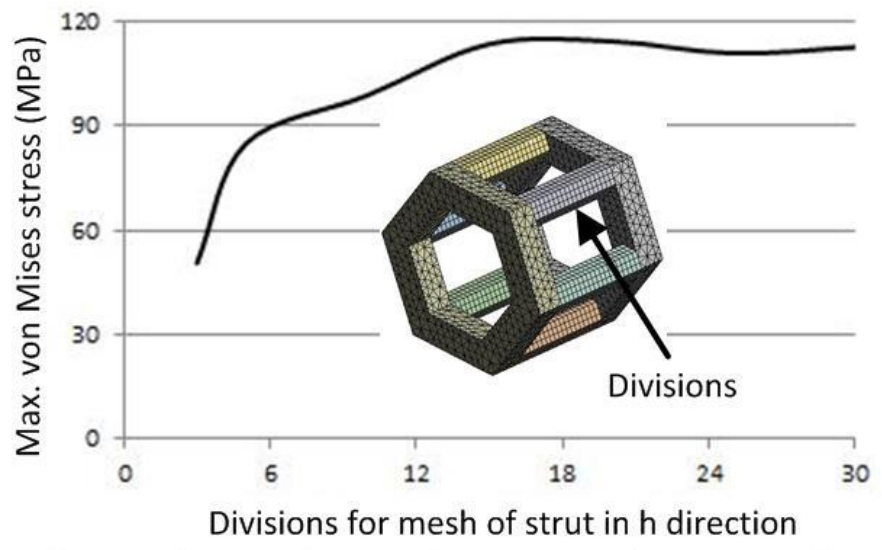

Fig. 2 Mesh-sensitivity study by maximum stress to number of divisions for strut in $h$ direction.

\subsection{Loading cases}

In order to obtain the $E^{*}$ which will be defined in section 4 , the mechanical behaviour was investigated under axial tension and bending as shown in Fig. 3. In both cases, the left end was fixed and a force was axially applied on the other end. In the axial tension case, a concentrated force $F$, was applied as shown in Fig. 3(a). Fig. 3(b) shows the contour plot of displacement distribution by axially force $F$. In the bending case, the force was applied in two directions: perpendicular to the height, $h$, of the unit cell (Fig. 3(c)) and parallel to the height, h (Fig. 3(d)). The perpendicular force is referred to as $F_{V}$ and the parallel force is $F_{\mathrm{P}}$, where $F_{V}=F_{P}=200 \mathrm{~N}$.
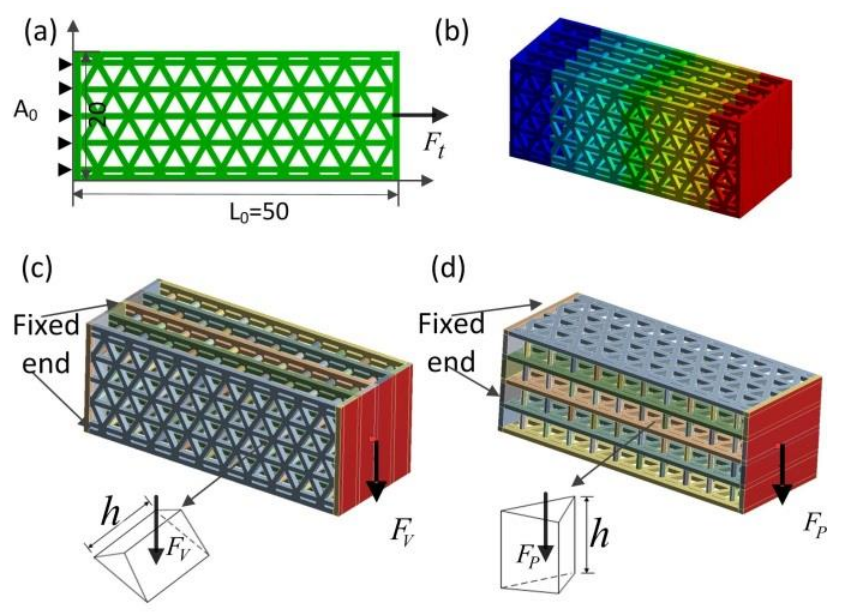

Fig. 3 Boundary conditions applied to FEA model, (a) boundary conditions with left side fixed and axial force on the right, (b) contour plot of displacement distribution under axial stretch, (c) bending test with left end fixed and concentrated force perpendicular to the height of unit cell, (d) bending test with left end fixed and concentrated force parallel to the height of unit cell.

\subsection{Simulation demonstrations}

Three cases of simulation experiments by FEA were implemented. Three unit cells [Triangular (T), Cubic (C), and Hexagonal $(\mathrm{H})$ ] are used to construct lattice structures with the same relative density (RD) [6], the same base areas $\mathrm{A}\left(\mathrm{A}_{\mathrm{T}}, \mathrm{A}_{\mathrm{C}}, \mathrm{A}_{\mathrm{H}}\right)$ of the unit cells and equal dimensions of the struts of the three unit cells.

\section{Case 1: $\mathbf{R D}_{\mathrm{T}}=\mathbf{R} \mathbf{D}_{\mathbf{C}}=\mathbf{R D}_{\mathbf{H}}$}


As listed in Table1, V11-V15, V21-V25, and V31-V35 are geometry parameters of five sampling points in each group of lattice structures with triangular unit cell (denoted as ' $\mathrm{T}$ ' and symbolized as ' $\Delta$ '), cubic unit cell (denoted as ' $\mathrm{C}$ ' and symbolized as ' $\square$ '), and hexagonal unit cell (denoted as ' $\mathrm{H}$ ' and symbolized as ' $\square$ '), respectively. RD for each group gradually increases from $20 \%$ to $60 \%$. RD is defined by the following formula:

$$
R D=\left(\frac{\rho^{*}}{\rho}\right) \times 100 \%
$$

where $\rho$ *is the effective density covered in the general dimensions of the lattice structures and can be measured by Creo®, $\rho$ is the density of the wall material.

For each given value of RD, there are many combinations of shape parameters making RDs of all the three lattice structures equal. Here $L$ and $h$ were kept extremely similar, but $t$ was varied. It can be seen that although RDs of lattice structures with different unit cells are all equal, the dimension may vary a lot. Particularly for each value of $\mathrm{RD}$, when $L$ and $h$ are slightly changed, $t_{\mathrm{T}}$ remains the smallest with the relation $t_{\mathrm{T}}<t_{\mathrm{C}}<t_{\mathrm{H}}$.

Table 1 Parameters of lattice structures of all three unit cells with the same RD.

\begin{tabular}{|c|c|c|c|c|c|}
\hline Cell shape & NO. & $L / \mathrm{mm}$ & $\mathrm{t} / \mathrm{mm}$ & $h / \mathrm{mm}$ & $\mathrm{RD} / \%$ \\
\hline \multirow{5}{*}{$\begin{array}{c}\text { Triangular } \\
(\mathrm{T}, \text { ' } \boldsymbol{\Lambda} \text { ') }\end{array}$} & V11 & 4.75 & 0.92 & 4.77 & 20 \\
\hline & V12 & 4.80 & 1.20 & 4.70 & 30 \\
\hline & V13 & 4.80 & 1.50 & 4.63 & 40 \\
\hline & V14 & 4.80 & 1.74 & 4.57 & 50 \\
\hline & V15 & 4.80 & 2.08 & 4.48 & 60 \\
\hline \multirow{5}{*}{$\begin{array}{c}\text { Cubic } \\
\left(\mathrm{C}, \boldsymbol{}^{\prime}{ }^{\prime}\right)\end{array}$} & V21 & 4.75 & 1.10 & 4.73 & 20 \\
\hline & $\mathrm{V} 22$ & 4.75 & 1.48 & 4.63 & 30 \\
\hline & V23 & 4.75 & 1.84 & 4.54 & 40 \\
\hline & V24 & 4.75 & 2.12 & 4.47 & 50 \\
\hline & V25 & 4.75 & 2.44 & 4.39 & 60 \\
\hline \multirow{5}{*}{ Hexagonal (H, ' ') } & V31 & 4.85 & 1.32 & 4.67 & 20 \\
\hline & V32 & 4.85 & 1.80 & 4.55 & 30 \\
\hline & V33 & 4.85 & 2.22 & 4.45 & 40 \\
\hline & V34 & 4.85 & 2.67 & 4.33 & 50 \\
\hline & V35 & 4.85 & 2.70 & 4.33 & 60 \\
\hline
\end{tabular}

\section{Case 2: $h_{\mathrm{T}}=h_{\mathrm{C}}=h_{\mathrm{H}}, \mathrm{A}_{\mathrm{T}}=\mathrm{A}_{\mathrm{C}}=\mathrm{A}_{\mathrm{H}}$}

When all lattice structures were designed with the same volume, namely $h_{\mathrm{T}}=h_{\mathrm{C}}=h_{\mathrm{H}}$ and $\mathrm{A}_{\mathrm{T}}=\mathrm{A}_{\mathrm{C}}=\mathrm{A}_{\mathrm{H}}$ as shown in Fig. 4 , the relation among $L_{\mathrm{T}}, L_{\mathrm{C}}$ and $L_{\mathrm{H}}$ can be derived by the following formulae.

Because

$A_{T}=A_{C}=A_{H}$

where

$$
A_{T}=\frac{\sqrt{3}}{4} L_{T}^{2}
$$



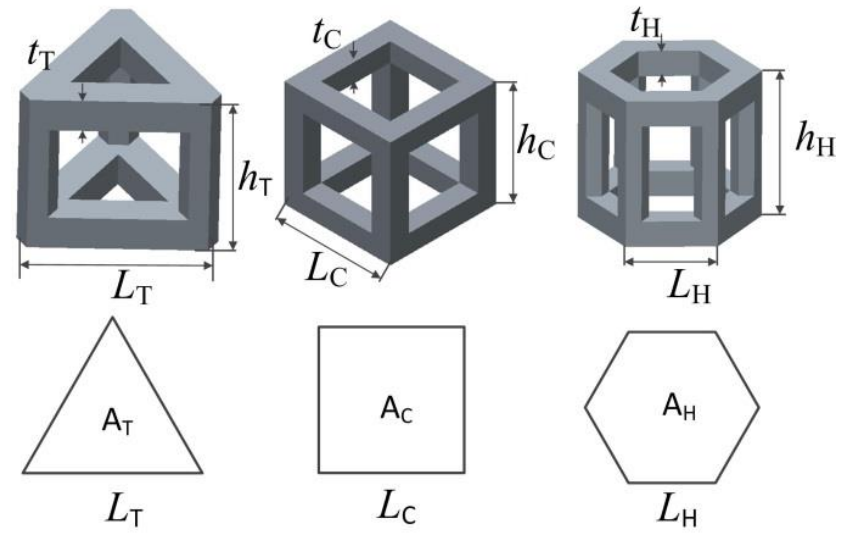

Fig. 4 Diagram of $h_{\mathrm{T}}=h_{\mathrm{C}}=h_{\mathrm{H}}, \mathrm{A}_{\mathrm{T}}=\mathrm{A}_{\mathrm{C}}=\mathrm{A}_{\mathrm{H}}$.

$$
A_{C}=L_{C}^{2}
$$

$A_{H}=\frac{3 \sqrt{3}}{2} L_{H}^{2}$

Hence, $L_{\mathrm{T}}$ and $L_{\mathrm{C}}$ can be represented by $L_{\mathrm{H}}$ as followings,

$$
\begin{aligned}
& L_{T}=\sqrt{6} L_{H} \\
& L_{C}=\sqrt{\frac{3 \sqrt{3}}{2}} L_{H}
\end{aligned}
$$

Then the magnitude relation of $L_{\mathrm{T}}, L_{\mathrm{C}}$ and $L_{\mathrm{H}}$ is:

$$
L_{H}<L_{C}<L_{T}
$$

From Eqs. (6) and (7), it can be seen that for a given value of $L_{\mathrm{H}}, L_{\mathrm{T}}$ and $L_{\mathrm{C}}$ can be obtained. The shapes of three unit cells are also determined by these given geometrical parameters. Supposed that RD is a constant, when the unit cell size is decreased, the number of unit cells with smaller cores and thinner struts will be increased. However, when the unit cell size is decreased to a very low value, the cores will become too small for the loose powder to be removed from the part following the completion of SLM [11].

\section{Case 3: $h_{\mathrm{T}}=h_{\mathrm{C}}=h_{\mathrm{H}}, L_{\mathrm{T}}=L_{\mathrm{C}}=L_{\mathrm{H}}, t_{\mathrm{T}}=t_{\mathrm{C}}=t_{\mathrm{H}}$}

The third comparison is to investigate on the differences of designs with all equal sizes of three unit cells as displayed in Fig. 5. The dimension relations of $h, L$ and $t$ can be expressed by Eq. (9).
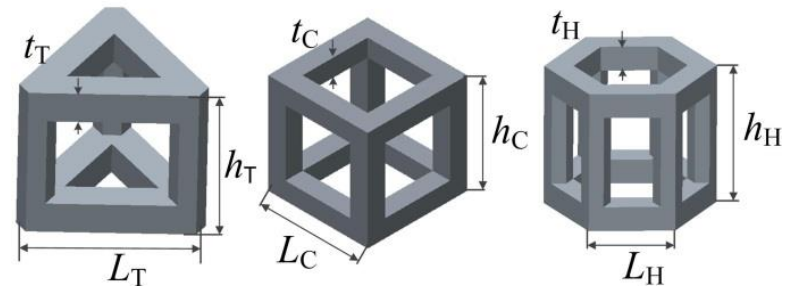

Fig. 5 Diagram of unit cells with equal size of all height, side length and strut thickness. 


$$
\left\{\begin{array}{c}
h_{T}=h_{C}=h_{H}=h \\
L_{T}=L_{C}=L_{H}=L \\
t_{T}=t_{C}=t_{H}=t
\end{array}\right.
$$

\section{Numerical results and discussion}

\subsection{Comparison with the same RD}

The FEA results based on case 1 are listed in Table 2. $E^{*}$ can be derived by the relation below [6],

$E^{*}=\frac{\sigma}{\varepsilon}=\left(\frac{F_{t}}{A_{0}}\right) /\left(\frac{\Delta L}{L_{T o t}}\right)$

where $\sigma$ is normal stress, $\varepsilon$ is axial strain, $F_{\mathrm{t}}$ is axial tension force, $A_{0}$ is the total area covered by the cross-section as shown in Fig. $3, L_{\text {Tot }}$ is the total length, and $\Delta L$ is the elastic tensile elongation.

In accordance with two loading conditions during bending, the results are also classified as case I for $F_{\mathrm{V}}$ and case II for $F_{\mathrm{P}} \cdot d_{V}^{*}$ is the predicted displacement based on $E^{*}, d \mathrm{v}$ is the calculated displacement using FEA and $\sigma_{\mathrm{v}, \max }$ is the maximum von Mises stress in the vertical direction. To evaluate the results and demonstrate the capabilities of these lattice structures, the assessed value of stiffness-to-mass ratio $R_{\mathrm{V}}$ is applied from [7]. In this paper, it is used to investigate the differences among these three unit cells filled structures by involving the critical results, the dependent relation between the force, the displacement and the responding weight. Here, $R_{\mathrm{V}}$ is given as:

$R_{V}=\left(\frac{F_{V}}{d_{V}}\right) / m^{*}$

where $m *$ is the weight of the lattice structure and can be obtained by RD. For a given force, there is an inverse proportion relationship between $R_{\mathrm{V}}$ and $d_{V}$ or $R_{P}$ and $d p$, as well as $m^{*}$. It can be stated that for a certain force and displacement, the smaller the value of $m^{*}$, the better the structure performs. In a similar way, for a certain force and mass, the smaller of $d \mathrm{v}$ or $d \mathrm{p}$, the structure performs better.

The $E^{*}$ of the lattice structures by FEA are graphed in Fig. 6, where symbol line ' $\mathrm{T}$ ', ' $\mathrm{C}$ ' and ' $\mathrm{H}$ ' denotes lattice structures with triangular, cubic and hexagonal unit cells respectively. $E^{*}$ increases with the increase of RD for all three types of unit cells. It may be a consequence of the increasing materials from cellular structure to bulk material $\left(\mathrm{E}^{*}=63 \pm 4 \mathrm{GPa}\right)$. It is worthy to note that, under this design and comparison method, the value of Young's modulus of lattice structure with triangular unit cell is always the biggest. 
Table 2 Mechanical performance of lattice structures with equal RD.

\begin{tabular}{|c|c|c|c|c|c|c|c|c|}
\hline \multirow[b]{2}{*}{ NO. } & \multirow{2}{*}{$\begin{array}{c}E^{*} \\
/ \mathrm{GPa}\end{array}$} & \multicolumn{4}{|c|}{ Vertical load Fig. 3(c) } & \multicolumn{3}{|c|}{ Parallel load Fig. 3(d) } \\
\hline & & $\begin{array}{c}d_{V}^{*} \\
/ \mathrm{mm}\end{array}$ & $\begin{array}{c}d \mathrm{v} \\
/ \mathrm{mm}\end{array}$ & $\begin{array}{l}\sigma_{\mathrm{v}, \max } \\
/ \mathrm{MPa}\end{array}$ & $R_{V}$ & $\begin{array}{c}d_{\mathrm{P}} \\
/ \mathrm{mm}\end{array}$ & $\begin{array}{l}\sigma_{\mathrm{p}, \max } \\
/ \mathrm{MPa}\end{array}$ & $R_{P}$ \\
\hline V11 & 7.34 & 0.097 & 0.091 & 114.3 & 194.2 & 0.338 & 233.9 & 49.6 \\
\hline V12 & 10.27 & 0.069 & 0.064 & 70.1 & 185.5 & 0.143 & 189.3 & 79.5 \\
\hline V13 & 16.94 & 0.042 & 0.039 & 49.4 & 285.9 & 0.064 & 176.9 & 168.5 \\
\hline V14 & 19.75 & 0.036 & 0.033 & 39.8 & 215.8 & 0.043 & 59.8 & 158.9 \\
\hline V15 & 30.09 & 0.024 & 0.022 & 25.6 & 272.8 & 0.024 & 26.4 & 238.4 \\
\hline $\mathrm{V} 21$ & 3.37 & 0.212 & 0.226 & 173.9 & 78.9 & 0.217 & 193.1 & 78.1 \\
\hline $\mathrm{V} 22$ & 7.03 & 0.102 & 0.093 & 76.4 & 128.5 & 0.090 & 89.3 & 128.5 \\
\hline $\mathrm{V} 23$ & 13.70 & 0.052 & 0.054 & 54.6 & 164.4 & 0.050 & 58.6 & 164.4 \\
\hline V24 & 18.73 & 0.038 & 0.040 & 41.1 & 196.4 & 0.040 & 48.6 & 189.6 \\
\hline V25 & 25.48 & 0.028 & 0.027 & 34.3 & 219.0 & 0.026 & 35.9 & 216.9 \\
\hline V31 & 4.07 & 0.175 & 0.160 & 230.0 & 113.5 & 0.256 & 306.0 & 67.8 \\
\hline V32 & 4.36 & 0.164 & 0.171 & 104.2 & 71.2 & 0.273 & 163.4 & 97.8 \\
\hline V33 & 11.81 & 0.060 & 0.056 & 53.9 & 161.0 & 0.069 & 80.8 & 125.1 \\
\hline V34 & 17.31 & 0.041 & 0.037 & 41.1 & 196.6 & 0.048 & 62.7 & 143.7 \\
\hline V35 & 22.58 & 0.032 & 0.029 & 30.6 & 207.8 & 0.036 & 42.0 & 160.4 \\
\hline
\end{tabular}

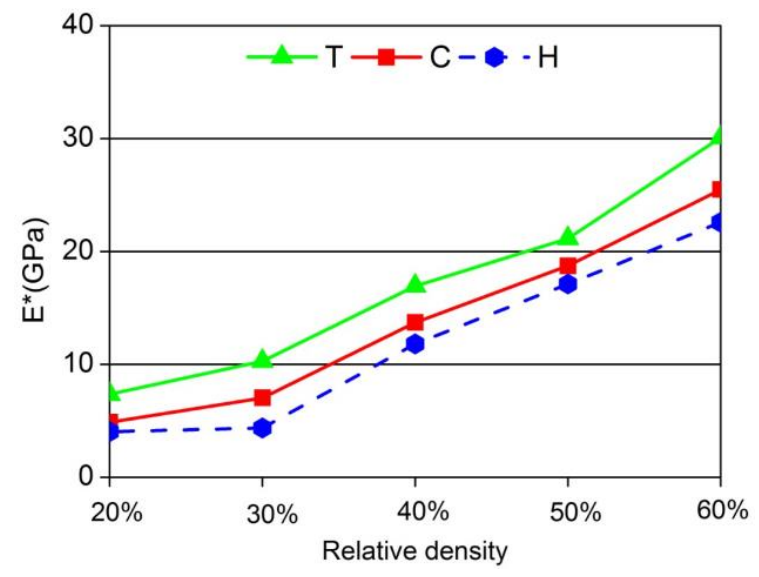

Fig. $6 \mathrm{E}^{*}$ to RD for the three lattice structures.

To validate the effectiveness of displacement $d_{V}^{*}$ by $E^{*}$, the total deformation by direct FEA and the relative error calculated using Eq. (12) are listed in Table 3. As the relative errors and average absolute errors are all within \pm $10 \%$, except one $11.2 \%$, it implies the good agreements between two calculation methods. Herein, $E^{*}$ can be the material input into the FEA analysis to evaluate the performance of the final part. It is consistent with the result by Parthasarathy et al. [39].

$\delta=\frac{d_{V}^{*}-d_{V}}{d_{V}} \times 100 \%$ 
Table 3 Comparison of displacements by $E^{*}$ and that by FEA.

\begin{tabular}{|c|c|c|c|c|c|c|c|c|c|}
\hline \multirow{2}{*}{$\mathrm{RD}(\%)$} & \multicolumn{3}{|c|}{ Lattice with triangular prism } & \multicolumn{3}{|c|}{ Lattice with square prism } & \multicolumn{3}{|c|}{ Lattice with hexagonal prism } \\
\hline & $d_{V} / \mathrm{mm}$ & $d_{V}^{*} / \mathrm{mm}$ & $81 \%$ & $d_{V} / \mathrm{mm}$ & $d_{V}^{*} / \mathrm{mm}$ & $\delta$ & $d_{V} / \mathrm{mm}$ & $d_{V}^{*} / \mathrm{mm}$ & $\delta / \%$ \\
\hline $20 \%$ & 0.086 & 0.093 & 7.1 & 0.215 & 0.202 & -6.3 & 0.153 & 0.167 & 9.4 \\
\hline $30 \%$ & 0.061 & 0.066 & 8.0 & 0.088 & 0.097 & 9.8 & 0.163 & 0.156 & -4.1 \\
\hline $40 \%$ & 0.038 & 0.040 & 6.8 & 0.052 & 0.050 & -3.9 & 0.054 & 0.058 & 8.1 \\
\hline $50 \%$ & 0.032 & 0.034 & 8.3 & 0.04 & 0.036 & 3.4 & 0.035 & 0.039 & 11.2 \\
\hline $60 \%$ & 0.021 & 0.023 & 8.1 & 0.026 & 0.027 & 1.9 & 0.027 & 0.03 & 9.4 \\
\hline$\overline{|\delta|}$ & & & 7.7 & & & 5.0 & & & 8.4 \\
\hline
\end{tabular}

According to Table 2 and Fig. 7, the maximum stress decreases with increasing RD, which can be explained by the increased materials. It is also noted that the maximum stress of triangular unit cell under $F_{\mathrm{V}}$ is at the minimum for each group with the same RD, even though it has the smallest $t_{\mathrm{T}}$ (Table 1) compared with the other two prisms. Another interesting result is that, for all unit cells in each group, the stress level under $F_{\mathrm{V}}$ is lower than that of force $F_{\mathrm{P}}$, revealing the anisotropy property of this design. The reason for this phenomenon lies in the triangular unit cell within the in $x y$ plane (Fig. 1). It gives good support by proper stability of the triangle, while only reduces non loadbearing materials by isolated struts in $\mathrm{z}$ direction. Fig. 7 also depicts that when RD is $20 \%$ or $30 \%$, the stress for all three unit cells are in high level, where stresses caused by $F \mathrm{v}$ are much smaller than that by $F \mathrm{p}$ for each unit cell. When RD increases to $40 \%, 50 \%$ to $60 \%$, the stresses by $F \mathrm{~V}$ and $F_{\mathrm{P}}$ become very close, showing that the shape and size difference become less obvious with regards to structure strength with the arising of bulk materials. It is also worth mentioning that the difference in stress in both directions for square prism structured part is the minimal among all. It can be explained by the symmetry and regularity of rectangle in each face of the square prism. Similar results were obtained by Parthasarathy et al. [39].

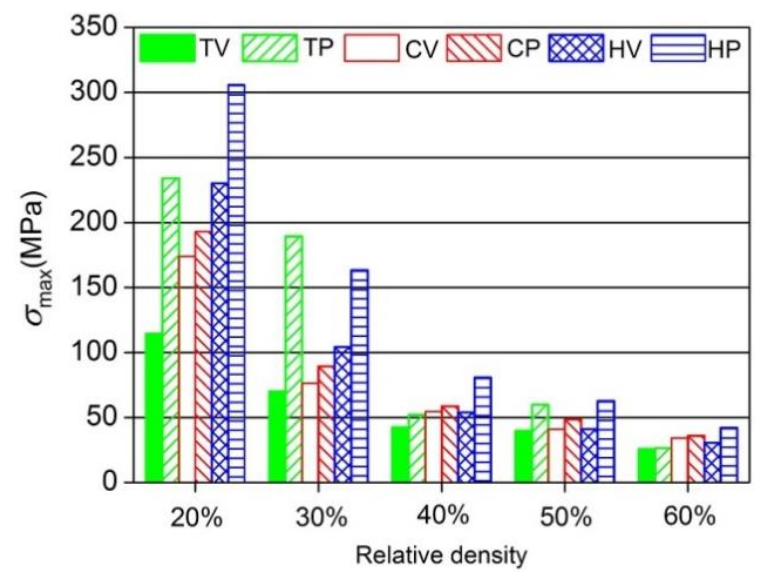

Fig. 7 Maximum von Mises stress to relative density (RD). (Note: TV/TP, CV/CP, HV/HP mean the values of $\sigma_{\max }$ were obtained for lattice structures with triangular prism, cubic prism and hexagonal prism under vertical/parallel force, respectively)

In Table 2 and Fig. 8, the value of strength-to-weight, $R$, relation is proportional to relative density for all three unit cells, but with some minor differences. The strength-to-weight ratio of the conformal structure with triangular unit cells remains the maximum over the other two unit cells.

From the results in Table 2, Fig. 6 and Fig. 8, strength of lattice structure is closely and positively correlated to RD. In addition, the strength of each structure turns out to be dependent on the shapes of the unit cells. Therefore, it cannot be concluded that the mechanical properties can be derived purely based on the porosity of the lattice structure regardless of the cell shape. 


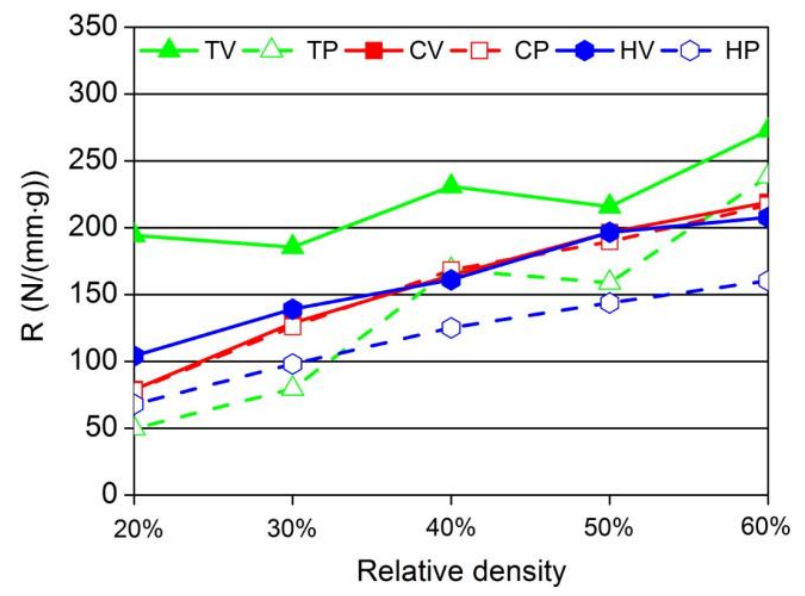

Fig. $8 \mathrm{R}$ to relative density (RD) of three types of unit cells. (Note: TV/TP, CV/CP, HV/HP mean the values of R were obtained for lattice structures with triangular prism, cubic prism and hexagonal prism under vertical/parallel force, respectively)

\subsection{Comparisons with the same volume}

In this section, thickness $t$ for all three unit cells is set as $1.0 \mathrm{~mm}, 1.2 \mathrm{~mm}$ and $1.4 \mathrm{~mm}$. For each given thickness, $L_{\mathrm{H}}$ is set as $2.0 \mathrm{~mm}, 2.2 \mathrm{~mm}, 2.4 \mathrm{~mm}, 2.6 \mathrm{~mm}$ and $2.8 \mathrm{~mm}$. The side lengths of $L_{\mathrm{T}}$ and $L_{\mathrm{C}}$ can be derived by Eq. (7) and (8). Fig. 9 shows the results by FEA with the same boundary conditions as section 3.3. For all graph in this paper, line symbols with ' $\mathrm{T}$ ', ' $\mathrm{C}$ ' and ' $\mathrm{H}$ ' indicate the property items $\left(\mathrm{RD}, \sigma, \mathrm{E}^{*}, \mathrm{R}\right)$ are based on lattice structures using triangular prism, cubic prism and hexagonal prism, while TV/TP, CV/CP, HV/HP stand for maximum von Mises stress of the lattice structures subjected to vertical/parallel force.

In Fig. 9(a), although the base areas and heights are all equal (identical volume) for lattice structures with hexagonal prism, cubic prism and triangular prism, the $\mathrm{RDs}$ are still distinguished that $\mathrm{RD}_{\mathrm{H}}$ (blue line) is the maximum, $\mathrm{RD}_{\mathrm{C}}$ (red line) is intermediate and followed by $\mathrm{RD}_{\mathrm{T}}$ (green line). It is opposite to the side length relation (Eq. (7)) with the same base area for all unit cells.

For the maximum stress under FV and FP in Fig. 9(b), when the thickness of the strut is given as $1.0 \mathrm{~mm}$, the maximum stress increases slightly with side length due to the small changed values. It was found that the maximum stress by vertical force is always smaller than that by parallel force with the same magnitude and this regulation is validated when thickness is given as $1.2 \mathrm{~mm}$ and $1.4 \mathrm{~mm}$. Among the strength performance, the stress level of the structure with triangular prism subjected to $F_{\mathrm{V}}$ is the lowest at every sampling point, while the triangular lattice prism performs the worst in out-plane direction, since the value of its maximum stress doubles than that in in-plane direction, so as to exceed the yield stress of AlSi10Mg (280 MPa) for most cases.

For $E^{*}$ in Fig. 9(c), when the strut thickness is $1.0 \mathrm{~mm}, E_{T}^{*}, E_{C}^{*}$ and $E_{H}^{*}$ decreases when side length increases from $2.0 \mathrm{~mm}$ to $2.8 \mathrm{~mm}$. This can be explained by the reduced materials (decreasing $\mathrm{RD}$ ) due to the increasing side length. The $E^{*}$ of structure with cubic prism is the maximum at each sampling point, followed by that with triangular prism and hexagonal prism. This relationship is the same when $t$ is $1.2 \mathrm{~mm}$ and $1.4 \mathrm{~mm}$.

In Fig. 9(d), when side length gradually varies from $2.0 \mathrm{~mm}$ to $2.8 \mathrm{~mm}$, the stiffness-to-mass ratio of lattice structure with triangular unit cell (T, green line) attains greater value over that of other lattice structures with cubic prism (C, red line) and hexagonal prism $(\mathrm{H}$, blue line) in general. It is notable that the values of all stiffness-to-mass ratios vary in a certain and stable range. More specifically, both $R_{\mathrm{C}}$ and $R_{\mathrm{H}}$ range from $100 \mathrm{~N} /(\mathrm{mm} \cdot \mathrm{g})$ to $150 \mathrm{~N} /(\mathrm{mm} \cdot \mathrm{g})$, while $R_{T}$ varies from $150 \mathrm{~N} /(\mathrm{mm} \cdot \mathrm{g})$ to $200 \mathrm{~N} /(\mathrm{mm} \cdot \mathrm{g})$, where $R_{T}$ presents larger at points $2.0 \mathrm{~mm}$ and $2.8 \mathrm{~mm}$ than that at the other points. It reveals that triangular prism replaced lattice structure exhibits the dominant advantages, the lesser bulk material and the smaller displacement, with the same design constrains and loads conditions. But for lattice structures with triangular unit cells, the change in $t$ does not really affect the $\mathrm{R}_{\mathrm{V}}$. The others are slightly increased in the $R_{\mathrm{V}}$ with increasing of $t$. When $L_{\mathrm{H}}$ changed from $2.0 \mathrm{~mm}$ to $2.8 \mathrm{~mm}$, the $\mathrm{RV}$ of lattice structures with 
triangular unit cells has significant differences at $2.0 \mathrm{~mm}$ and $2.8 \mathrm{~mm}$. This result discloses the importance of parameter ranges for experimental of lattice structures with triangular unit cells.

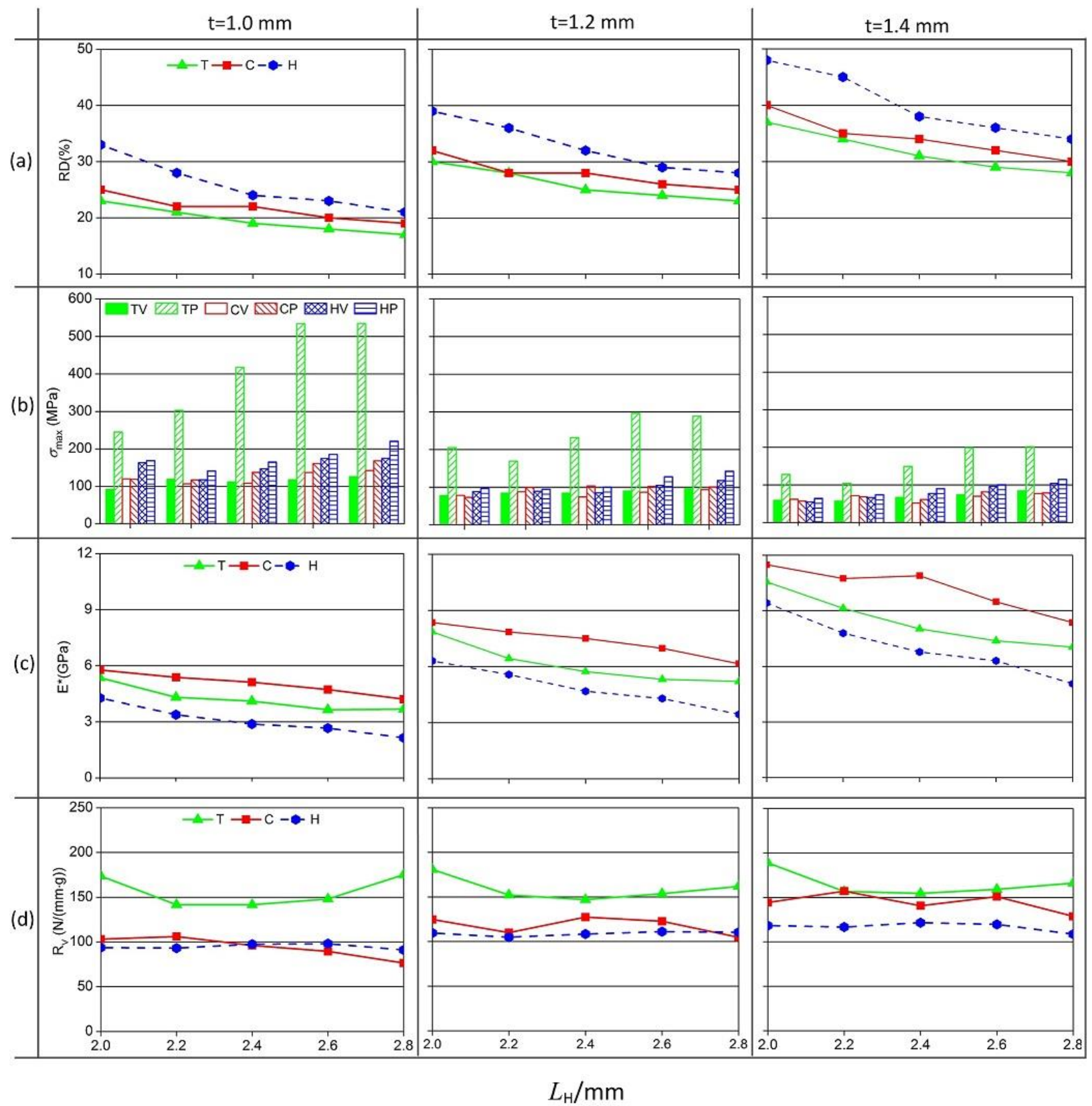

Fig. 9 Comparison of (a) relative density RD, (b) maximum stress under $F_{\mathrm{V}}$ and $F$ p, (c) effective Young's modulus $E^{*}$, and (d) stiffness-to-mass ratio under $F_{\mathrm{V}}$ with equal base areas of all three kinds of unit cells.

\subsection{Comparisons with all equal dimensions of all unit cells}

The constraints that all geometrical parameters in the same items are equal for different spatial unit prism is to make detailed comparisons of geometry differences and the responding mechanical properties as listed in Fig. 10. Figs. $10(a),(b),(c)$ and (d) are the relative densities, maximum stress, $E^{*}$ and stiffness-to-mass ratio, respectively. 
In Fig. 10(a), $\mathrm{N}=5$ and $\mathrm{t}=1.0 \mathrm{~mm}$, where $\mathrm{h}$ is determined by $\mathrm{N}$ and $\mathrm{t}$ in RVE. For points $L=3.5$ to $4.7 \mathrm{~mm}, \mathrm{RD}$ gradually decreases for all unit cell types. The same tendency is repeated when $\mathrm{N}=7$ and $t=1.0 \mathrm{~mm}$. The declines of $\mathrm{RD}$ of structures with all three prisms result from the increasing side length of the unit cells. As the values of side length of all three types of unit cells are equal, the base area of triangular unit cell is the smallest according to Eq. (3) to Eq. (5). Hence the total number of unit cells covered in the beam-like bending structures. Therefore the $\mathrm{RD}_{\mathrm{T}}$ is always bigger than $\mathrm{RD}_{\mathrm{C}}$ and $\mathrm{RD}_{\mathrm{H}}$ for all sampling points.

In Fig. $10(\mathrm{~b})$, when $\mathrm{N}=5, t=1.0 \mathrm{~mm}, \sigma_{\mathrm{TV}}$ varies from around $75 \mathrm{MPa}$ to $120 \mathrm{MPa}$ at each sampling point and remains the minimal compared with $\sigma_{\mathrm{TC}}$ and $\sigma_{\mathrm{TH}}$. Distinguished from design with the same base area for all unit cells, the worst condition occurs to lattice structures with hexagonal prism subjected to parallel force, where $\sigma_{\mathrm{HP}}$ is twice as $\sigma_{\mathrm{HV}}$. As $\sigma_{\mathrm{HP}}$ exceeds the yield strength $\left(\sigma_{\mathrm{s}}=338 \mathrm{MPa}\right)$ for the last three sampling points, the values of $\sigma_{\mathrm{HP}}$ are meaningless. In this case, the conformal lattice structures with triangular prism tend to be a preferable option with regard to structural strength. When $\mathrm{N}=7, \mathrm{t}=1.0 \mathrm{~mm}$, the relative density increases with the added two layers, as graphed in Fig. 10(b). The maximum stresses are all reduced at every data point compared with that when $\mathrm{N}=5$ and $\mathrm{t}=1.0 \mathrm{~mm}$, due to the increment of materials in the restricted volume. Likewise, stress level of model with triangular prism subjected to vertical force continues to be the lowest. Based on above results and analysis, the mechanical properties under vertical force are referred in Fig. 10(c) and (d). Fig. 10(c) shows the dominant strength in terms of $E^{*}$ of parts with triangular prism, which is followed by that with cubic prism and finally followed by hexagonal prism.

Finally in Fig. 10(d), for the given five sampling points, when $\mathrm{N}=5, \mathrm{t}=1.0 \mathrm{~mm}, \mathrm{R}_{\mathrm{T}}$ ranges from $150 \mathrm{~N} /(\mathrm{mm} \cdot \mathrm{g})$ to 200 $\mathrm{N} /(\mathrm{mm} \cdot \mathrm{g})$, and has the distinct advantages over structures designed with other two unit cells, which are around 100 $\mathrm{N} /(\mathrm{mm} \cdot \mathrm{g})$. It is interesting to note that for cubic, $E^{*}$ is much higher than for $\mathrm{H}$, but the specific strength is quite similar for both. While it should be emphasized that there is no remarkable difference in terms of the value of stiffness-to-mass ratio between $\mathrm{N}=5$ and $\mathrm{N}=7$ with other same shape parameters. In this respect, using triangular prism to fill the conformal cellular structure is preferential design when the shape parameters are all equal for all proposed unit cells.

\section{Experimental testing and validation}

\subsection{Material and specimen manufacturing}

To verify the effectiveness of using FEA for prediction of the mechanical properties of the lattice structures, some samples were selected and manufactured by SLM technique using AlSi10Mg powders. The composition of the powders are listed in Table 4 [44]. The size range is 20-63 $\mu \mathrm{m}$. Due to its near eutectic elements of $\mathrm{Al}$ and $\mathrm{Si}$, it shows good weldability. Minor additions of $\mathrm{Mg}(0.20-0.45 \%)$ allow hardenability through natural or artificial ageing [41].

Table 4 Chemical composition of the AlSi10Mg powders [44].

\begin{tabular}{cccccccccc}
\hline Element & $\mathrm{Al}$ & $\mathrm{Si}$ & $\mathrm{Mg}$ & $\mathrm{Cu}$ & $\mathrm{Fe}$ & $\mathrm{Mn}$ & $\mathrm{Zn}$ & $\mathrm{Ti}$ & Others \\
\hline wt\% & Bal. & $9-11$ & $0.20-0.45$ & 0.05 & 0.55 & 0.45 & 0.10 & 0.15 & 0.3 \\
\hline
\end{tabular}

Due to the relatively low strength of the meshed structures and the insufficient length to be fixed by the grips as shown in Fig. 11(a), two side caps were directly extended to $20 \mathrm{~mm}$ as Fig. 11 (b). In this case, the shrinkage will occur during the manufacturing as displayed in Fig. 11(c). The solid material shrinkage could be a larger degree during solidification, but there is little shrinkage within the meshed regions at the boundaries due to small volume. Hence, the solid-meshed interface may be under some residual stresses, which may affect the mechanical performance of the final samples. A possible solution is to use an extensometer of $25 \mathrm{~mm}$ during the tensile tests. Because the total length of the lattice structure is $50 \mathrm{~mm}$, it is easy to guarantee the relatively good condition of the workpieces by taking gauge length of $25 \mathrm{~mm}$ from the central area. 


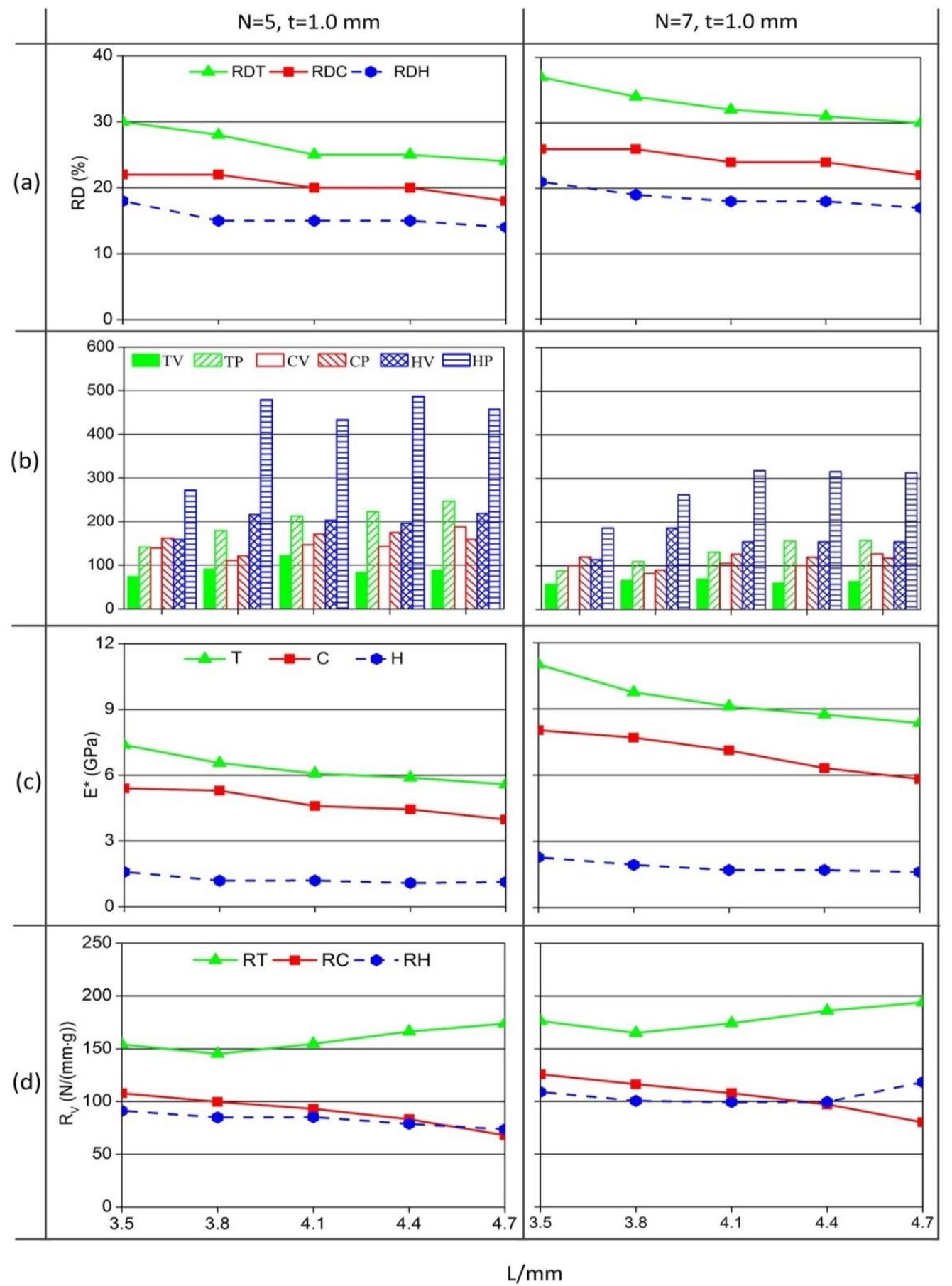

Fig. 10 Comparisons of (a) relative density $\mathrm{RD}$, (b) maximum stress under $F \mathrm{v}$ and $F \mathrm{p}$, (c) effective Young's modulus $E^{*}$, and (d) stiffness-to-mass ratio under $F_{\mathrm{V}}$ with equal dimensions of all three kinds of unit cells. 
(a)
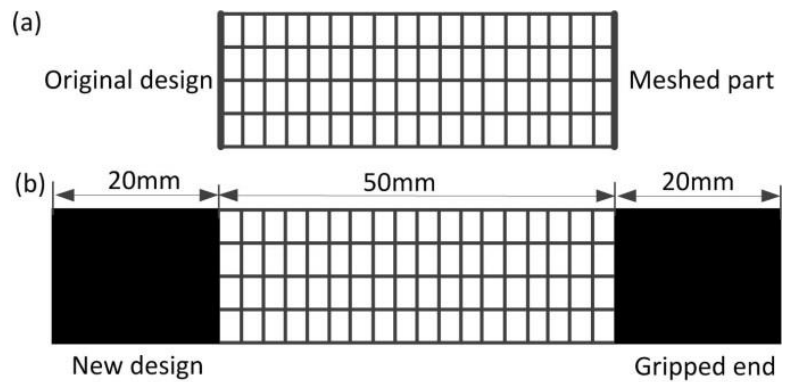

(c)

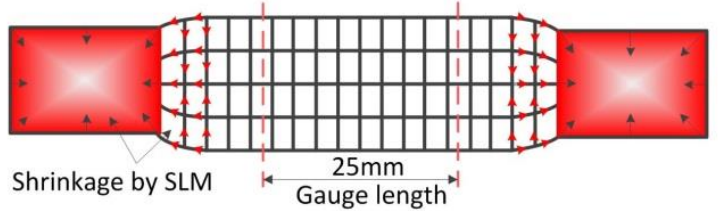

Fig. 11 Modified design for manufacturing and tensile test with the consideration of shrinkage during manufacturing: (a) original model with meshed unit cells used in FEA, (b) solutions with solid ends for gripping in tensile tests, (c) post-manufacturing with residual stress at the cooled ends and the solid-meshed interface.

With AlSi10Mg powders and STL models of the three designs placed in diagonal direction, the standard printing parameters with SLM280HL were applied as follows:

Laser energy density of $60 \mathrm{~J} / \mathrm{mm}^{3}$.

Laser beam diameter of $\varnothing 0.1 \mathrm{~mm}$.

Layer thickness of $30 \mu \mathrm{m}$.

Argon gas shielding.

Table 5 Design parameters of the manufactured specimens.

\begin{tabular}{llllll}
\hline NO. & $L / \mathrm{mm}$ & $h / \mathrm{mm}$ & $t / \mathrm{mm}$ & $R D / \%$ & $E_{\text {FEA }} / \mathrm{GPa}$ \\
\hline Sample 1 & 5.88 & 3.80 & 1.00 & 19 & 4.11 \\
Sample 2 & 2.20 & 3.80 & 1.00 & 28 & 3.38 \\
Sample 3 & 4.90 & 3.70 & 1.40 & 37 & 10.56 \\
\hline
\end{tabular}

Finally, three samples after post-processing for comparative study as stated in case 2 and results in section 4.2 are displayed in Fig. 12 (a). The shape of the unit cell, geometry parameters and $E^{*}$ according to above numerical results are listed in Table 5. It can be seen that all selected lattice structures were successfully fabricated with fine features. The shrinkage due to the thermal dissipation during the fabrication process did not significantly affect the final general dimensions.

\subsection{Bulk tensile testing and results}

These specimens were then stretched under room temperature using an Instron 5985 universal testing machine with a $250 \mathrm{kN}$ load cell. A constant deformation rate of $1 \mathrm{~mm} / \mathrm{min}$ was used with $25 \mathrm{~mm}$ extensometer. With both solid ends gripped, the samples were axially extended until broken. As the lattice structures are much weaker compared with solid materials, the deformation tends to exceed the maximum extension once yields. Hence the extensometer was removed after obvious yielding. Otherwise, the extensometer could slide over the sample and affect the stability of testing. The fractures of lattice structures in Fig. 12(b) are all located in the transition regions consistent with the shrinkage effects as stated in Fig. 11. 

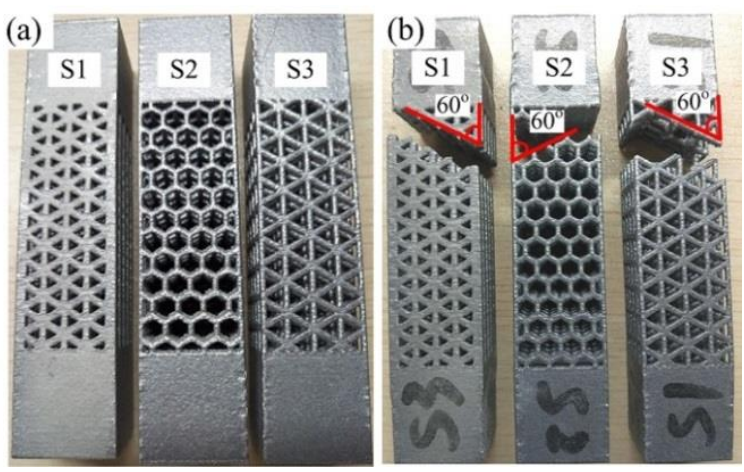

Fig. 12 Prototypes manufactured by SLM process: (a) photos of the samples in front view, (b) picture of samples tested to failure.

Taking a specific looking at the fracture surfaces, it was found that the fracture angles are all about $60^{\circ}$ along the boundary of the unit cell. It is quite different from the classical fracture angle of $45^{\circ}$ for solid metals. As the focus of this paper is on linear elastic deformation of the lattice structures, the fracture behaviour will not be further discussed here.

\subsection{Comparison of the bulk tensile curves and effective Young's modulus}

The load-extension curves and the converted stress-strain curves of all three samples are plotted in Fig. 13(a) and (b) respectively. Fig. 13(a) describes the whole extension curves of the samples between two gripped ends. It was used to expose how the structure behaved from elastic to plastic and finally fracture. Fig. 13(b) mainly plots the elastic stress-strain relations which were the key region studied in this paper. To be
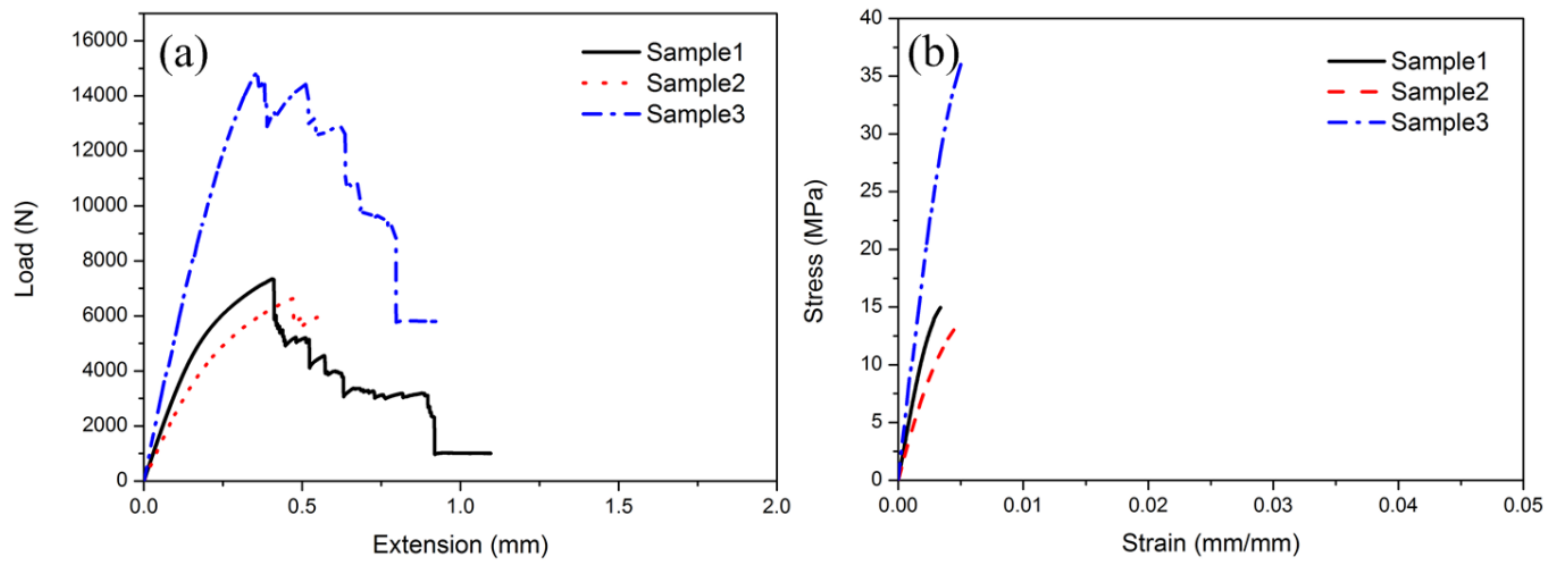

Fig. 13 Tensile tests of SLM printed AlSi10Mg samples, (a) load-extension curves observed between two gripped ends and (b) converted stress-strain curves mainly in elastic region obtained by extensometer of $25 \mathrm{~mm}$ gauge length.

From both types of curves, it can be seen that the curves show regular initial elastic behaviour before yielding. Then the mechanical performances are quite different from the traditional bulk materials and become extremely irregular. As the initial elastic regions still present regular linearity, it is possible to calculate $E^{*}$ by linear regression. The values of $E^{*}$ both by numerical simulation and experimental test, as well as the relative errors are presented in Fig. 14. The relative errors of $E^{*}$ obtained by both methods are less than $10 \%$, showing good correlation between FEA and experimental results. 


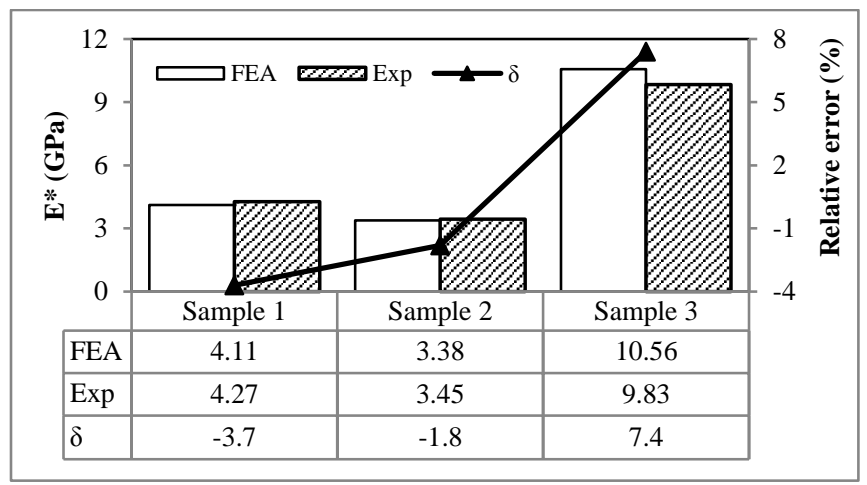

Fig. 14 Results by simulation and experimental testing and the relative errors.

In general, the simulation results agree very well with the experimental results, implying that the material properties of the cellular structure are consistent and predictable. It also indicates that the boundary conditions applied to the FEA models are reasonable.

\section{Discussions}

When the conformal lattice structures were designed with the same RD for all unit cells discussed in this paper, the Young's modulus, maximum von Mises stress and stiffness-to-mass ratio were differently affected by shape parameters of unit cells. Among all three comparisons of design methods with regular unit cells, the in-plane performances of conformal lattice structures with all three unit cells revealed better structure strength than that in out-plane direction or along the parallel force. Particularly, the stress value of lattice structure with triangular prism remains the smallest in this case.

Relative density is an essential factor to determine the strength of lattice structures. However, it is not a sufficient condition alone. Firstly, suppose the RDs of the lattice structures are all equal as stated in Case 1, the mechanical properties were still varied due to different unit cell shapes. Secondly, even for the same unit cell with the same RD, the mechanical performance is also discrepant. It's owing to variations of geometrical parameters used to determine dimensions and shapes of the unit cells. For instance, when $\mathrm{RD}_{\mathrm{V}}$ is $30 \%$ in Table $1(\mathrm{~V} 12)$, where $\mathrm{N}=5, L_{\mathrm{T}}=4.8 \mathrm{~mm}$ and $t_{T}=1.2 \mathrm{~mm}$, the value of $E^{*}$ is $10.76 \mathrm{GPa}$, the maximum stress is $70.1 \mathrm{MPa}$ and the stiffness-to-mass ratio is $194.8 \mathrm{~N} /(\mathrm{mm} \cdot \mathrm{g})$. And in Fig. 10, when $\mathrm{N}=5, L_{\mathrm{T}}=3.5 \mathrm{~mm}$ and $t_{T}=1.0 \mathrm{~mm}$, where $\mathrm{RD}_{\mathrm{V}}$ is also $30 \%$, but $E^{*}$ is 7.73 $\mathrm{GPa}$, the maximum stress is $74.6 \mathrm{MPa}$ and the stiffness-to-mass ratio is $161.9 \mathrm{~N} /(\mathrm{mm} \cdot \mathrm{g})$. Also in Fig. 10, when $\mathrm{N}=7$, $L_{\mathrm{T}}=4.7 \mathrm{~mm}$ and $t_{T}=1.0 \mathrm{~mm}$, although the $\mathrm{RD}_{\mathrm{V}}$ is also $30 \%, E^{*}$ is $8.8 \mathrm{GPa}$, the maximum stress is $64.3 \mathrm{MPa}$ and the stiffness-to-mass ratio is $200.3 \mathrm{~N} /(\mathrm{mm} \cdot \mathrm{g})$. According to Fig. 9(a) (c) and Fig. 10(a) and (c), the values of $E^{*}$ are all proportional to relative density, which is similar to the conclusion for triangular honeycomb by Hunt [13] and Gibson et al [17]. It is noticed that the impact of RD on stress are different for different unit cells. For example, in Fig. 9(a), the value of $\mathrm{RD}_{\mathrm{H}}$ at each sampling point is the greatest, followed by $\mathrm{RD}_{\mathrm{C}}$ and $\mathrm{RD}_{\text {T. }}$ In contrast, the value of $E_{C}^{*}$ (Fig. 9(c)) is the biggest followed by $E_{T}^{*}$ and $E_{C}^{*}$. While in Fig. 10(a), when the shape parameters of the unit cells are all equal, value of $\mathrm{RD}_{\mathrm{T}}$ is the followed by $\mathrm{RD}_{\mathrm{C}}$ and $\mathrm{RD}_{\mathrm{H}}$, their values of Young's modulus rank in the same order. Herein, the strength of a cellular material with certain unit cell is dependent on the shape parameters, not only on its RD.

For conformal lattice structure with triangular prism, its Young's modulus in section 4.1 (Fig. 6) and section 4.3 (Fig. 10(c)) show the maximum value and that in section 4.2 (Fig. 9(c)) present the intermediate value. However, the stiffness-to-mass ratios always exhibit better performance over the other two types of unit cells accordingly. A conclusion can be drawn that for a given load-bearing structure and proposed design constraints, building the lightweight conformal cellular structures with triangular prism unit cells is the best option compared to cubic and hexagonal ones Namely triangular lattice structures have value of high $E^{*}$ by axial tension, lower stress level and the dominant stiffness-to-mass ratio, compared with the commonly used cubic and hexagonal unit cells in structural applications by AM technology. 
To get insight into the mechanism of the advantage of conformal lattice structure with triangular prism, the stress contours of three types of lattice structures obtained from FEA are listed in Fig. 15. All the three models have the same base area of unit cells, the same number of layers in the out-plane direction, as well as the same loads and boundary conditions. It is obvious that the maximum stress locations for all three cases are all within in lower fixed end. The hexagonal lattice structure in Fig. 15(a) has the largest number of unit cells followed by cubic lattice structure in Fig. 15(b). While triangular lattice structure has the fewest and weights the least which is in good accordance with RD relations as graphed in Fig. 9(a). The maximum stress of model with hexagonal unit cell is 165 MPa (Fig. 15(a)). While that with cubic unit cell is $120 \mathrm{MPa}$ (Fig. 15(b)) and that with triangular unit cell is only 92 MPa (Fig. 15(c)). In this aspect, replacing the solid materials with triangular prism is potentially the best solution, regarding to structural strength with the same area of three proposed conformal methods in meso-scale. Besides, the displacements of models in $d_{\mathrm{H}}$ (Fig. 15 (a)), $d_{\mathrm{C}}$ (Fig. 15 (b)) and $d_{\mathrm{T}}$ (Fig. 15 (c)) have the relation $d_{\mathrm{H}}>d_{\mathrm{C}}>$ and $d_{\mathrm{T}}$. Herein, the shape of the unit cell has a high impact on the strength performance of the lattice structure.

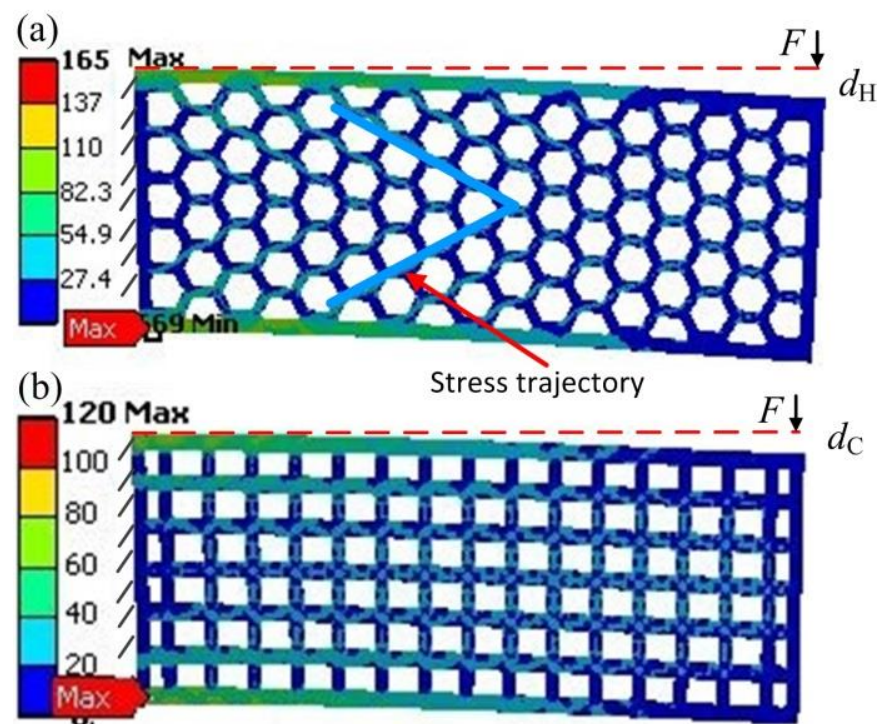

(c)

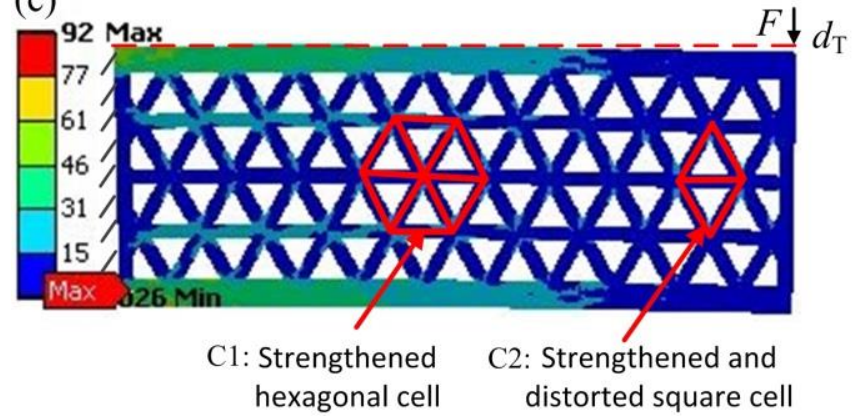

Fig. 15 Comparison of maximum stress and maximum displacement under $F \mathrm{~V}$ with equal base area of (a) triangular unit cell, (b) cubic unit cell and (c) hexagonal unit cell.

In Fig. 15(a), the regions with relatively larger stress form a triangular profile as highlighted in blue lines, indicating that there is a certain stress trajectory for this beam-like bending structure. In Fig. 15(b), due to the symmetry of square prism, the stress is evenly distributed in most of the cells. In other words, most of the cells are activated to support the bending load. It is confirmed by the relatively better mechanical properties as discussed in section 4.1, section 4.2 and section 4.3. In Fig. 15(c), most of the inner struts show the intermediate value of von Mises stress, reflecting that these inner-connected lattice struts are all participating in bearing the load. In addition, the thickness of the top and bottom edges is thicker compared to other structures in Fig. 15(a) and (b), leading to smaller stress due to larger bearing cross-section accordingly. However, this is just a special case. For other values of geometrical parameters, this significant superiority for the replaced structure with greater thickness may not exist. Fundamentally, the special internal struts of lattice structured material with triangular prism maintain the basic 
advantages. Interesting to note in Fig. 15(c), the inter-connected triangular unit cells form the shape of hexagonal unit cells which are strengthened by inner strut as highlighted in Fig. 15(c) c1. Besides, equilateral parallelogram is also included in the scaled triangular unit cells but is distorted and strengthened by one inner strut as highlighted in Fig. 15(c) c2. Therefore, based on the stress trajectory in Fig. 15(a), stress distribution in all three contours in Fig. 15, and unique inter-connected struts, using triangular lattice method to create the tailored and conformal cellular structure is a preferable approach for a load-bearing beam in terms of mechanical performance, such as Young's modulus, maximum stress and value of stiffness-to-mass ratio.

\section{Conclusions}

To take the advantage of lightweight design method based on lattice structures by additive manufacturing, the mechanical performances of three potential unit cells were investigated. In this work, a design method was proposed for the uniformly replaced beam-like lattice structures by three unit cells, triangular prism, square prism and hexagonal prism. The numerical results revealed that when the new conformal design was begun with equal relative density, the vertical displacements according to $E^{*}$ by axial tensile force were in great agreement with that by direct calculation of FEA for all three conformal methods. The relative errors were all within $\pm 10 \%$, showing that it was reasonable to use $E^{*}$ for calculation of bending of lattice structures. When the design was begun with equal area and height, although the lattice structure with triangular prism had the minimal relative density and the median of Young's modulus, it still had the lowest stress level under the vertical end force and achieved the maximum stiffness-to-mass ratio. It should be noticed that this cellular method performed the worst under parallel force. When design was begun with the same dimensions of side length of all three unit cells, not only the Young's modulus of triangular prism conformal structure ranked the maximum, but the stiffness-to-mass ratio also presented the maximum value. The good agreements between the calculated $E^{*}$ and experimental results validated the FEA method applied. The relative density is proportional to $E^{*}$, which is, however, more reliable on shapes and parameters of unit cell. As a conclusion, the lattice structure with triangular unit cell is the best in terms of minimum stress and maximum stiffness-to-mass ratio under vertical force subjected to one end of the beam-like structure. It was observed in experiments that the initial fracture frequently occurred at transition region between meshed part and solid ends, where there is a big difference of stiffness. The $E^{*}$ proposed in this paper can be used to estimate load transmission and the deformation of bulk material with number of unit cells greater than $2 \times 5 \times 2$, i.e. 2 rows, 5 volumes and 2 layers. This is extremely useful in the initial analysis of the lattice structures made of these unit cells at the design stage. However, it cannot represent the local stress concentration within the unit cells and therefore accurate fatigue life calculation cannot be obtained either. Further work may include the comparison among more unit cells, such as recently developed re-entrant auxetic lattice structure [1] and body-centred cubic lattice structure [27]. The fundamental study of triangular lattice structures would also be carried out by theoretical analysis and experimental testings in the future.

\section{References}

1. Yang, L., Harrysson, O., Cormier, D., et al., Additive Manufacturing of Metal Cellular Structures: Design and Fabrication. Jom, 2015. 67(3): p. 608-615.

2. Gervasi, V.R. and Stahl, D.C. Design and fabrication of components with optimized lattice microstructures. in Proceedings of the Solid Freeform Fabrication Symposium. 2004. Austin, TX.

3. $\quad$ Li, Z., Zhang, D.Z., Dong, P., et al., A lightweight and support-free design method for selective laser melting. The International Journal of Advanced Manufacturing Technology, 2016: p. 1-11.

4. Rosen, D.W. Design for additive manufacturing: A method to explore unexplored regions of the design space. in Eighteenth Annual Solid Freeform Fabrication Symposium. 2007.

5. Hao, L. and Raymond, D. Design and additive manufacturing of cellular lattice structures. in The International Conference on Advanced Research in Virtual and Rapid Prototyping (VRAP). Taylor \& Francis Group, Leiria. 2011.

6. Choi, J. and Chae, T.-S., Effective stiffness and effective compressive yield strength for unit-cell model of complex truss. International Journal of Mechanics and Materials in Design, 2015. 11(1): p. 91-110.

7. Reinhart, G. and Teufelhart, S., Load-adapted design of generative manufactured lattice structures. Physics Procedia, 2011. 12: p. 385-392.

8. Nguyen, J., Park, S.-i., and Rosen, D., Heuristic optimization method for cellular structure design of light weight components. International Journal of Precision Engineering and Manufacturing, 2013. 14(6): p. 1071-1078. 
9. Park, S.-I., Rosen, D.W., Choi, S.-k., et al., Effective mechanical properties of lattice material fabricated by material extrusion additive manufacturing. Additive Manufacturing, 2014. 1: p. 12-23.

10. Luxner, M.H., Stampfl, J., and Pettermann, H.E., Finite element modeling concepts and linear analyses of $3 D$ regular open cell structures. Journal of Materials science, 2005. 40(22): p. 5859-5866.

11. Yan, C., Hao, L., Hussein, A., et al., Evaluations of cellular lattice structures manufactured using selective laser melting. International Journal of Machine Tools and Manufacture, 2012. 62: p. 32-38.

12. Giannitelli, S., Accoto, D., Trombetta, M., et al., Current trends in the design of scaffolds for computeraided tissue engineering. Acta biomaterialia, 2014. 10(2): p. 580-594.

13. Hunt, H., The mechanical strength of ceramic honeycomb monoliths as determined by simple experiments: Advanced materials. Chemical engineering research \& design, 1993. 71(3): p. 257-266..

14. Yan, C., Hao, L., Hussein, A., et al., Microstructure and mechanical properties of aluminium alloy cellular lattice structures manufactured by direct metal laser sintering. Materials Science and Engineering: A, 2015. 628: p. 238-246.

15. Brennan-Craddock, J., Brackett, D., Wildman, R., et al. The design of impact absorbing structures for additive manufacture. in Journal of Physics: Conference Series. 2012. IOP Publishing.

16. Alzahrani, M., Choi, S.-K., and Rosen, D.W., Design of truss-like cellular structures using relative density mapping method. Materials \& Design, 2015. 85: p. 349-360.

17. Gibson, L.J. and Ashby, M.F., Cellular solids: structure and properties. 1999: Cambridge university press.

18. Jin, T., Zhou, Z., Wang, Z., et al., Experimental study on the effects of specimen in-plane size on the mechanical behavior of aluminum hexagonal honeycombs. Materials Science and Engineering: A, 2015. 635: p. 23-35.

19. Ju, J. and Summers, J.D., Compliant hexagonal periodic lattice structures having both high shear strength and high shear strain. Materials \& Design, 2011. 32(2): p. 512-524.

20. Brenne, F., Niendorf, T., and Maier, H.J., Additively manufactured cellular structures: Impact of microstructure and local strains on the monotonic and cyclic behavior under uniaxial and bending load. Journal of Materials Processing Technology, 2013. 213(9): p. 1558-1564.

21. Li, P., Constitutive and failure behaviour in selective laser melted stainless steel for microlattice structures. Materials Science and Engineering: A, 2015. 622: p. 114-120.

22. Ahmadi, S.M., Campoli, G., Amin Yavari, S., et al., Mechanical behavior of regular open-cell porous biomaterials made of diamond lattice unit cells. J Mech Behav Biomed Mater, 2014. 34: p. 106-15.

23. Gibson, L.J. and Ashby, M. The mechanics of three-dimensional cellular materials. in Proceedings of the Royal Society of London A: Mathematical, Physical and Engineering Sciences. 1982. The Royal Society.

24. Ashby, M.F. and Medalist, R.M., The mechanical properties of cellular solids. Metallurgical Transactions A, 1983. 14(9): p. 1755-1769.

25. Onck, P., Andrews, E., and Gibson, L., Size effects in ductile cellular solids. Part I: modeling. International Journal of Mechanical Sciences, 2001. 43(3): p. 681-699.

26. Youssef, S., Maire, E., and Gaertner, R., Finite element modelling of the actual structure of cellular materials determined by X-ray tomography. Acta Materialia, 2005. 53(3): p. 719-730.

27. Smith, M., Guan, Z., and Cantwell, W.J., Finite element modelling of the compressive response of lattice structures manufactured using the selective laser melting technique. International Journal of Mechanical Sciences, 2013. 67: p. 28-41.

28. Eshraghi, S. and Das, S., Micromechanical finite-element modeling and experimental characterization of the compressive mechanical properties of polycaprolactone-hydroxyapatite composite scaffolds prepared by selective laser sintering for bone tissue engineering. Acta biomaterialia, 2012. 8(8): p. 3138-3143.

29. Gorguluarslan, R.M., Gandhi, U.N., Mandapati, R., et al., Design and fabrication of periodic lattice-based cellular structures. Computer-Aided Design and Applications, 2016. 13(1): p. 50-62.

30. Evans, A.G., Hutchinson, J.W., Fleck, N.A., et al., The topological design of multifunctional cellular metals. Progress in Materials Science, 2001. 46(3): p. 309-327.

31. Wang, H., Chen, Y., and Rosen, D.W. A hybrid geometric modeling method for large scale conformal cellular structures. in ASME 2005 International Design Engineering Technical Conferences and Computers and Information in Engineering Conference. 2005. American Society of Mechanical Engineers.

32. Williams, C.B., Cochran, J.K., and Rosen, D.W., Additive manufacturing of metallic cellular materials via three-dimensional printing. The International Journal of Advanced Manufacturing Technology, 2011. 53(1): p. 231-239.

33. Zok, F.W., Rathbun, H.J., Wei, Z., et al., Design of metallic textile core sandwich panels. International Journal of Solids and Structures, 2003. 40(21): p. 5707-5722. 
34. Seepersad, C.C., Kumar, R.S., Allen, J.K., et al., Multifunctional design of prismatic cellular materials. Journal of Computer-Aided Materials Design, 2004. 11(2): p. 163-181.

35. Lee, S., Barthelat, F., Moldovan, N., et al., Deformation rate effects on failure modes of open-cell Al foams and textile cellular materials. International Journal of Solids and Structures, 2006. 43(1): p. 53-73.

36. Read, N., Wang, W., Essa, K., et al., Selective laser melting of AlSilOMg alloy: Process optimisation and mechanical properties development. Materials \& Design, 2015. 65: p. 417-424.

37. Niu, J., Choo, H.L., and Sun, W., Finite element analysis and experimental study of plastic lattice structures manufactured by selective laser sintering. Proceedings of the Institution of Mechanical Engineers, Part L: Journal of Materials: Design and Applications, 2017. 231(1-2): p. 171-178.

38. Deshpande, V.S., Fleck, N.A., and Ashby, M.F., Effective properties of the octet-truss lattice material. Journal of the Mechanics and Physics of Solids, 2001. 49(8): p. 1747-1769.

39. Parthasarathy, J., Starly, B., and Raman, S., A design for the additive manufacture of functionally graded porous structures with tailored mechanical properties for biomedical applications. Journal of Manufacturing Processes, 2011. 13(2): p. 160-170.

40. Wang, D., Yang, Y., Liu, R., et al., Study on the designing rules and processability of porous structure based on selective laser melting (SLM). Journal of Materials Processing Technology, 2013. 213(10): p. 1734-1742.

41. Brandl, E., Heckenberger, U., Holzinger, V., et al., Additive manufactured AlSilOMg samples using Selective Laser Melting (SLM): Microstructure, high cycle fatigue, and fracture behavior. Materials \& Design, 2012. 34: p. 159-169.

42. Maskery, I., Aboulkhair, N.T., Corfield, M.R., et al., Quantification and characterisation of porosity in selectively laser melted Al-SilO-Mg using X-ray computed tomography. Materials Characterization, 2016. 111: p. 193-204.

43. Kempen, K., Thijs, L., Van Humbeeck, J., et al., Mechanical Properties of AlSiloMg Produced by Selective Laser Melting. Physics Procedia, 2012. 39: p. 439-446.

44. Solutions, S. SLM Metal Powder 2016; Available from: https://slm-solutions.com/products/accessoriesand-consumables/slm-metal-powder. 